Results Two hundred of 245 (81.6\%) included women completed the baseline and three-month questionnaires. The incidence of lymphedema was $7.2 \%$ versus $31.5 \%$ in women who underwent SLN mapping alone and completion PL, respectively $(\mathrm{p}<0.001)$. Lymphedema scores in the leg, genital, and groin were affected in both groups, but significantly more after PL. The differences between groups remained significant in a multivariate analysis adjusting for, e.g., adjuvant therapy and age. PL significantly affected the severity of lymphedema regarding physical performance $(\mathrm{p}=0.001)$, appearance $(\mathrm{p}=$ 0.008 ), besides heaviness, weakness, and pain in the legs ( $p<$ 0.001). Lymphedema was negatively associated with impaired body image, physical, role, and social functioning and a higher level of fatigue.

Conclusions SLN mapping combined with PL is associated with a significantly higher incidence and more severe lymphedema three months postoperatively than SLN mapping alone. Lymphedema was associated with lower QoL in several domains.

\section{EPV050/\#255 OVERUSE OF CERVICAL CANCER SCREENING TESTS AMONG AVERAGE-RISK MEDICAID BENEFICIARIES}

1J Dillon, $2,3,4$ J Wright, ${ }^{2} \mathrm{~L}$ Chen, ${ }^{3} \mathrm{M}$ Accordino, ${ }^{2} \mathrm{~A}$ Melamed, ${ }^{3} \mathrm{D}$ Hershman. ${ }^{1}$ Duke University School of Medicine, School of Medicine, Durham, USA; ${ }^{2}$ Columbia University College of Physicians and Surgeons, Gynecologic Oncology, New York City, USA; ${ }^{3}$ Herbert Ining Comprehensive Cancer Center, Oncology, New York City, USA; ${ }^{4}$ New York Presbyterian Hospital, Oncology, New York City, USA

\subsection{6/ijgc-2021-IGCS.118}

Objectives In 2012, the American Cancer Society updated cervical cancer screening guidelines to recommend cytologic screening every 3 years or HPV testing with cytology (co-testing) every 5 years in women age 30-65. We aim to examine the use of cervical cancer screening among average-risk Medicaid beneficiaries.

Methods The MarketScan database was used to identify average-risk women age 30-64 with Medicaid coverage who underwent index cervical cancer screening in 2013-2016. Subsequent screening rates within 3 years of the index test were examined. Demographic factors associated with early re-screening and rates of annual gynecologic examinations were also

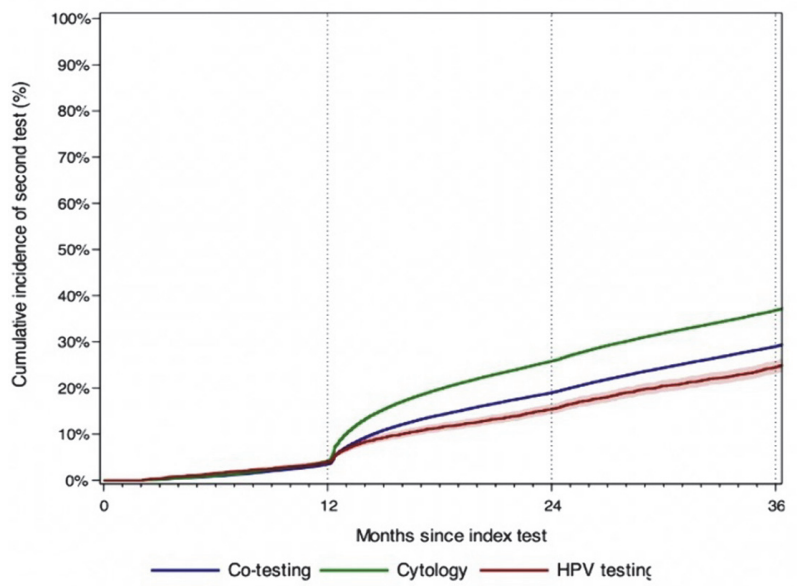

Abstract EPV050/\#255 Figure 1 Cervical cancer screening by month examined. Patients with cervical dysplasia, HPV, or unsatisfactory results were excluded.

Results Overall, 265,083 patients were included. 43.1\% $(\mathrm{N}=114,312)$ had index co-testing, 55.2\% ( $\mathrm{N}=146,309)$ had cytology, and $1.7 \%(\mathrm{~N}=4,462)$ had primary HPV testing. The cumulative incidence of early, repeat cervical cancer screening was $3.9 \%$ at $12 \mathrm{mo}, 22.7 \%$ at $24 \mathrm{mo}$, and $33.3 \%$ at $36 \mathrm{mo}$. During the period from 12-24 months after follow-up, 20.9\% of women underwent repeat screening, while $19.4 \%$ underwent screening 24-36 months after the index test. Early retesting was more common in younger patients and non-White patients $(p<0.001)$. of patients who did not undergo repeat cervical cancer screening, a yearly gynecologic examination was performed in only 16,627 (10.7\%) during year 2 and in $11,116(8.8 \%)$ patients during year 3 .

Conclusions Among average-risk Medicaid beneficiaries, cervical cancer screening is frequently overutilized. Women who do not undergo cervical cancer screening are unlikely to receive routine gynecologic care.

\section{EPV051/\#264 SMALL CELL NEUROENDOCRINE CARCINOMA OF THE CERVIX IN A YOUNG PATIENT WITH UTERINE PROCIDENTIA: A CASE REPORT}

M Garcia*, I Tagayuna. Tondo Medical Center, Obstetrics and Gynecology, Manila, Philippines

\subsection{6/ijgc-2021-IGCS.119}

Objectives Small cell neuroendocrine carcinoma of the cervix (SCNC) is an aggressive and rare histologic subtype, accounting for less than $2 \%$ of all cervical tumors. Moreover, cervical cancer complicated with uterine prolapse is even rarer with an estimated incidence of $0.14-1.0 \%$.

Methods A 32-year-old multipara presented with a 13-month history of intermittent vaginal spotting and postcoital bleeding, associated with gradually increasing introital mass. Pelvic examination revealed procidentia uteri. A foul-smelling fungating, necrotic mass at the anterior lip of the cervix measuring $9 \times 9 \times 4.5 \mathrm{~cm}$ was also noted. Biopsy of the mass and

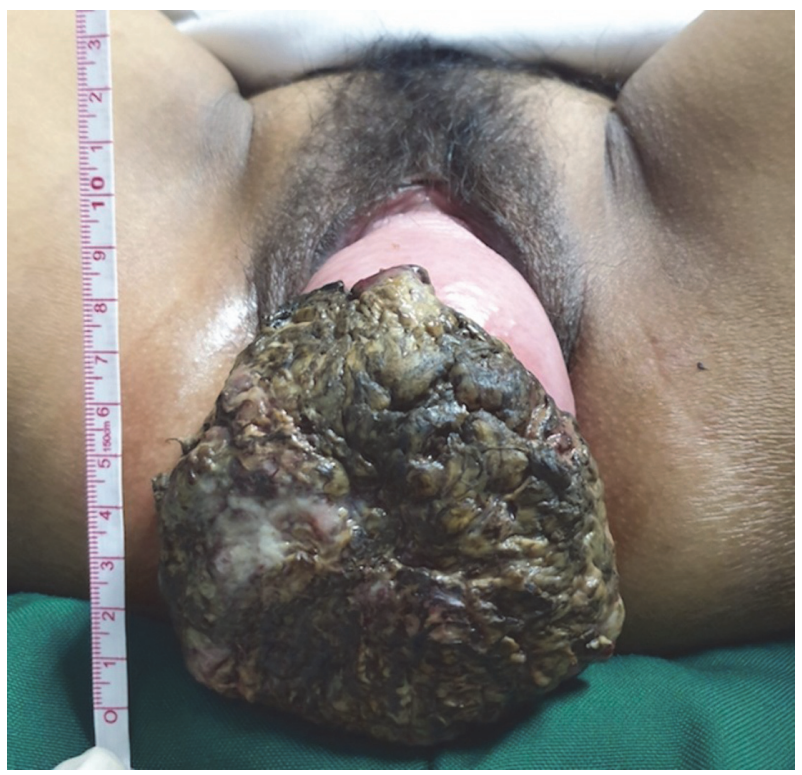

Abstract EPV051/\#264 Figure 1 